\title{
Control of Nematodirus spp. infection by sheep flock owners in Northern Ireland
}

\author{
Connor McMahon ${ }^{1}$, Hillary W. J. Edgar², Jason P. Barley², Robert E. B. Hanna², Gerard P. Brennan \\ and lan Fairweather ${ }^{1 *}$
}

\begin{abstract}
Background: To address a lack of information on the control of ovine helminth parasites in Northern Ireland (NI), a number of research projects have been undertaken, dealing with gastrointestinal nematodes, tapeworms and liver fluke. This investigation concerns Nematodirus and concentrates on three aspects of disease: farm management strategies for its control, derived from the results of a Questionnaire; the efficacy of treatment used by farmers, as determined by a coprological survey; and the hatching requirements of Nematodirus eggs, that is, whether prolonged chilling is a pre-requisite for hatching.
\end{abstract}

Results: A Questionnaire was sent to 252 sheep farmers in NI in March 2012 (covering the years 2009-2012) and replies were received from 228 farmers. Under-dosing, inaccurate calibration of equipment and inappropriate product choice were poor practices identified. Following this survey, the efficacy of treatment of Nematodirus spp. in sheep flocks was evaluated in April and May 2012. Sampling kits were sent to 51 flock owners, all of whom returned pre- and post-anthelmintic dosing faecal samples to the laboratory for analysis. At the time of treatment, 41 flocks were positive for Nematodirus (as diagnosed by the presence of eggs). Reduced benzimidazole efficacy was detected in $35.7 \%$ of flocks tested $(n=28)$. Although only involving a small number of flocks, reduced efficacy of levamisole treatment was detected in 50\%, of avermectins in 33\% and of moxidectin in $75 \%$ of flocks tested ( $n=2,6$ and 4 , respectively). In the egg hatch experiment, carried out under "chilled" and "non-chilled" conditions, 43\% of the eggs in the "non-chilled" group were able to hatch, compared to $100 \%$ in the "chilled" group.

Conclusions: The identification of inefficient control strategies argues for continued education of stockholders, in order to improve their management programmes. This is particularly important where the practices might impact on the development of anthelmintic resistance, which has been shown to exist on NI farms. The appropriate choice of anthelmintic is a vital part of this plan. The ability of eggs to hatch under non-chilled conditions demonstrates a flexibility in hatching behaviour. This may represent an adaptation to climate change and account for the recent emergence of a second, autumnal peak of infection.

Keywords: Nematodirus spp., Survey, Questionnaire, Northern Ireland, Faecal egg count reduction test, Egg hatch behaviour

\section{Background}

In relation to published data on the control of helminth parasite disease in livestock, historically, Northern Ireland (NI) has lagged behind the rest of the United Kingdom (UK) and the Republic of Ireland (ROI). There is little information on topics such as the epidemiology

\footnotetext{
*Correspondence: i.fairweather@qub.ac.uk

${ }^{1}$ Parasite Therapeutics Research Group, School of Biological Sciences, Medical Biology Centre, The Queen's University of Belfast, 97 Lisburn Road, Belfast BT9 7BL, UK

Full list of author information is available at the end of the article
}

(and changing pattern) of disease, the prevalence of disease, the level of anthelmintic resistance (AR) in parasite populations and what management strategies are in place to control disease. This is surprising, given that the NI economy is more dependent upon agriculture than any other region of the UK, as seen through its share of the economy, employment and business base [1]. The gross value added (GVA) of the combined Agriculture and food/drink processing industry was $3.5 \%$ to the GVA for NI, and employment was 6\% [2]. Beef and sheep meat encompass the largest sector of the Agri- 
Food industry: $£ 394 \mathrm{~m}$ and $£ 63 \mathrm{~m}$ was accrued from finished cattle and finished sheep in 2015, respectively [3]. The gathering of data in relation to parasitic diseases is of vital importance to the design and development of effective and sustainable programmes for parasite control. That is, programmes that will enable farmers to maximise animal welfare and productivity, yet will mitigate dependence on drug use, and thereby serve to slow the progression of AR.

The results of some recent studies on ovine helminth parasites in NI have begun to fill in the gaps in our knowledge. Climate change has been shown to have altered the seasonal pattern of some diseases: for example, an extension of the traditional transmission window for trichostrongylosis/teladorsagiosis; the emergence of a second, autumnal peak in Nematodirus spp. infection; and a shift in chronic fasciolosis to earlier in the year [4-6]. A coprological survey carried out in July-October 2011 provided information on the prevalence of AR in gastrointestinal nematode infections in sheep [7]. A Questionnaire survey (conducted between May-September 2011) examined patterns of anthelmintic drug use and the effectiveness of management strategies in place to control the diseases $[8,9]$. However, the timing of the coprological survey in 2011 precluded the collection of data in relation to Nematodirus spp.

In sheep flocks in the UK and elsewhere in Europe, also Canada and the Rocky Mountain States of the USA, the most common aetiological agent of nematodirosis is Nematodirus battus [10]. While Nematodirus helvetianus, $N$. filicollis and $N$. spathiger have been noted in mixed infections in these areas, they are considered to be more common across Australasia. Nematodirus spp. are considered to be atypical among trichostrongylid nematodes as a result of their long generation time, development to $\mathrm{L}_{3}$ larvae within the egg and (presumed) requirement of a period of chilled temperatures, followed by a sustained daily average temperature of $10{ }^{\circ} \mathrm{C}$ or more before hatching will take place $[11,12]$. Nematodirosis is predominantly a disease of young lambs in the Spring; immunity develops quickly [13] and this results in adult stock playing a negligible role in epidemiology [14]. N. battus infection is an important cause of clinical disease (resulting from scouring and reduced weight gain) and fatality in young lambs in spring, following the mass hatch of infective $\mathrm{L}_{3}$ larvae [15].

Relatively little is known about nematodirosis in NI. Diagnoses of nematodirosis (as a percentage of all ovine submissions to the Agri-Food and Biosciences Institute (AFBI) in NI and The Department of Agriculture, Food and the Marine (DAFM) Laboratories in the ROI) were $16 \%, 11 \%$ and $16 \%$ higher in NI than the RoI in 2013 , 2014 and 2015, respectively [16-18]. In terms of the percentage of all ovine endoparasitic disease, nematodirosis in NI stands at $22 \%$, compared to $27 \%$ for PGE (caused by other trichostrongylid nematodes); for the ROI, the figures are $6 \%$ and $52 \%$, respectively [18]. The data suggests that nematodirosis is more prevalent in the North of Ireland than in the South.

It has been shown that up to $\sim 70 \%$ of all deposited eggs will hatch without the chilling stimulus [19] and it has been suggested that the phenotypic plasticity in $N$. battus hatching behaviour represents a "bet-hedging" strategy that allows the establishment of "chilled" larvae in parasite-naive lambs, supplemented by infection later in the season by larvae produced from "non-chilled" eggs [20]. In recent years, increasingly, outbreaks of nematodirosis have been seen later in the grazing season (or indeed in the Autumn) in older lambs [20-27]. This has already been reported for NI [4].

Control of nematodirosis is achieved through the use of anthelmintic drugs, most commonly benzimidazoles (BZs). In contrast to the situation in other trichostrongylid nematodes, there have been relatively few reports of AR in Nematodirus spp. In the Southern Hemisphere, oxfendazole resistance was found on a sheep farm in New Zealand [28], and Nematodirus spp. were found to be resistant to oxfendazole, thiabendazole and fenbendazole in a survey conducted on sheep farms in Australia [29]. Furthermore, a total of 8 isolates of BZ-resistant $N$. spathiger (with a small contribution to total parasite burden by $N$. abnormalis) were reported in Tasmania [30, 31]. More recently, BZ (albendazole) resistance has been demonstrated in $N$. spathiger and $N$. filicollis in New Zealand [32]. In the Northern Hemisphere, anthelmintic failure against $N$. battus has been reported in the UK and the ROI; in the UK, it was linked with (the impact of) "intestinal hypermotility on the pharmacokinetics of relatively insoluble drugs", rather than to AR per se [33]. Similarly, evidence for reduced efficacy of levamisole (LV) and macrocyclic lactone (ML) treatments has been observed in the ROI, with suboptimal dosing practices put forward as a potential explanation [34, 35]. Recently, a fenbendazole-resistant $N$. battus isolate was identified in Scotland [36]. A subsequent clinical efficacy trial and pyrosequencing analysis revealed a high frequency of homozygous resistant genotypes, demonstrating that the F200Y Single Nucleotide Polymorphism (SNP) may be a potential mechanism of resistance in Nematodirus spp. [37].

The overall aim of the current investigation was to obtain more information on ovine nematode disease control in NI, by focussing on Nematodirus. The study examined three specific topics: the efficiency of management practices in use by farmers, as gathered from the results of a Questionnaire; the efficacy of treatment of $N$. battus populations, as determined by means of a coprological survey; and the hatching requirements of $N$. battus eggs, that is, whether chilling is essential for 
hatching of the eggs. The results of the latter experiment may shed light on the underlying cause of the changing pattern of infection in response to climate change, a second, autumnal peak of infection having been identified previously [4].

\section{Methods}

\section{Questionnaire}

Following the analysis of data collated from a Provincewide Questionnaire survey in 2011, a supplementary set of questions was sent (in March 2012) to those respondents who farmed sheep. The supplementary questions were presented in 3 sections, namely, control of Nematodirus spp. (Section 1), control of ectoparasites (Section 2) and control of tapeworm parasites (Section 3). This manuscript is only concerned with the responses to questions in Section 1.

\section{Statistical analysis of questionnaire data}

Descriptive statistics, such as means and standard deviations, were calculated using Microsoft ${ }^{\circ}$ Excel 2007.

\section{Coprological survey Survey population}

Through the completion and return of a Questionnaire, participants had indicated a willingness to have their flocks tested for the presence of anthelmintic-resistant Nematodirus spp. populations. On receipt of a completed questionnaire at the Veterinary Sciences Division (VSD), Stormont, flock owners were sent sample packs which contained a general overview of the test methodology. Following this, each flock owner was contacted by telephone to discuss the specific requirements of the testing protocol. No limitations were placed on the owners as to when they were to collect pre-treatment samples (regarding the time elapsed since the last anthelmintic treatment), or which product was to be used for treatment. Similarly, the only criterion for inclusion in the study was that a questionnaire was completed beforehand. No further selection of participants took place. The intent of this was to ensure inclusion of a diverse range of flock types, including pedigree, commercial and mixed flocks, as well as a range of flock sizes. Coprological testing took place between April 1st and May 31st 2012.

\section{Instructions to flock owners}

Calibration of dosing equipment (for products to be given orally) was to be performed, before treatment, using the drench of choice at its recommended dose rate. Flock owners were to dispense $20 \mathrm{ml}$ of anthelmintic solution into a graduated measuring device, to ensure the appropriate volume was being delivered. To minimise under-dosing, flock owners were asked to weigh the animals (by weigh-bridge) and to dose to the weight of the heaviest animal in the group, as per SCOPS (Sustainable Control Of Parasites in Sheep) guidelines [38]. Ideally, the animals were to be selected from the 2011 lamb crop and should represent a broad cross-section of the flock, not only those animals showing visible scour. A minimum of 20 animals were to be separated, individually marked by coloured spray-marker, the ear-tag number recorded and ten $50 \mathrm{ml}$ universal sample pots were to be used to store ten faecal samples, one sample from each of 10 lambs. The samples were collected from the ground following defaecation after observation of the animals. For the post-treatment (pt) sampling, as many as possible of the initial ten lambs were to be resampled, although if it were not possible to collect from the initial ten, individuals from the remainder of the group were to be used as replacements [7]. Between sample times, the animals were to have full access to pasture already grazed that year. After collection, farmers were asked not to refrigerate samples, but to return them as soon as possible to the laboratory at VSD (AFBI), where the faecal egg counting was carried out.

Instructions on re-sampling times for the various drench classes were set as 7 days (d) following treatment, regardless of product selection. This follows SCOPS advice to "retest seven to 10 days (no longer, because of the short prepatent period of $N$. battus) after the administration of the drench." $[39,40]$.

\section{Sample processing}

The sedimentation method for fluke eggs, as described by Flanagan et al. [41], was used for counting Nematodirus spp. eggs. Briefly, $3 \mathrm{~g}$ of faeces was added to $42 \mathrm{ml}$ of water and homogenised, before passing the solution through a strainer and collecting a $15 \mathrm{ml}$ sample in a test-tube. The sample was washed through a $90 \mu \mathrm{m}$ sieve set over a $63 \mu \mathrm{m}$ sieve, before inverting the $63 \mu \mathrm{m}$ sieve and washing the filtrate into a bowl. The bowl contents were poured into a pint beaker and left to sediment for a minimum of 15 min. Eggs of Nematodirus spp. were counted and the number of eggs per gram (epg) was calculated. In order to check that all Nematodirus eggs were trapped and retained on the $63 \mu \mathrm{m}$ sieve, the content remaining on the $90 \mu \mathrm{m}$ sieve and the residue washed through the $63 \mu \mathrm{m}$ sieve were regularly examined to confirm the absence of Nematodirus eggs. The detection limit of the method is $15 \mathrm{epg}$.

\section{Faecal egg count reduction test (FECRT)}

Percentage reduction was based on the formula of Kohapakdee et al. [42]: percentage reduction $=[(\mathrm{T} 1-\mathrm{T} 2) / \mathrm{T} 1]$ $\times 100$, where T1 is the arithmetic mean Faecal Egg Count (FEC) pre-treatment and T2 is the arithmetic mean FEC of treated animals. This formula has been used in previous 
studies [7, 8, 43]. Resistance is confirmed when the reduction in FECs pt. is less than 95\% and the lower 95\% confidence interval of the percentage reduction is less than $90 \%$ [44].

\section{Outlier identification}

For the purposes of this investigation, an outlier was defined as a data point that was numerically distant from the remainder of points within said dataset [7]. If an individual FEC was outside the range of the arithmetic mean \pm the standard error about the mean, it was not included in the efficacy calculation. Only pt. FECs were subject to outlier identification.

\section{Identification and initial characterization of ovine Nematodirus spp. present in Northern Ireland}

$N$. battus eggs were identified in FECs on the basis of egg morphology [45], and this was subsequently verified on the basis of $\mathrm{L}_{3}$ morphology [46].

The evaluation of egg hatching behaviour followed the protocol of van Dijk and Morgan [19]. Embryonation was carried out at $20{ }^{\circ} \mathrm{C}$. After 6 weeks, infective $\mathrm{L}_{3}$ larvae were visible in all eggs.

\section{Species identification}

Approximately 300 eggs were pipetted into a $2 \mathrm{ml}$ Eppendorf tube and stored at $4{ }^{\circ} \mathrm{C}$ for $29 \mathrm{~d}$, then transferred to a $13{ }^{\circ} \mathrm{C}$ incubator (Sanyo Incubator MIR-262; Sanyo Electric Biomedical Co. Ltd., Japan). At d 60, the eggs were stained in Lugol's iodine for $20 \mathrm{~min}$, counterstained in $30 \%(w / v)$ sodium thiosulphate, and then the hatched larvae were examined microscopically for species identification [46]. N. battus was the only Nematodirus species detected.

\section{Hatching behaviour}

Faecal material remaining after the FECRT analysis was pooled from all the farms and so the data represents the NI population as a whole. The eggs were split equally into two groups: one group was maintained at $4{ }^{\circ} \mathrm{C}$ for $29 \mathrm{~d}$ (the "Chilled" group), while the other was kept at $20{ }^{\circ} \mathrm{C}$ for the same time period (the "Non-Chilled" group). The groups were then transferred to a $13{ }^{\circ} \mathrm{C}$ incubator. Plates were redistributed daily so as to minimise any effect of temperature flux within the incubator. The proportions of eggs containing larvae, and any larvae that had hatched, were counted on $\mathrm{d} 0$, and hatched larvae were thereafter counted on $\mathrm{d} 3$ and on alternate days up to $\mathrm{d} 41$. In order to determine whether the counts on d 41 represented the maximum hatch, further hatching was checked on d 50, 55 and 60 .

\section{Results}

Questionnaire results

A total of 228 completed questionnaires (from the initial 252 distributed) were received. This represents a return rate of $90.5 \%$. The summary of questions posed and responses received is presented in Table 1.

\section{Treatment timing}

The main influences on the decision of when to treat were: the presence of scour (47.4\%), AFBI forecast warnings of the peak hatching of Nematodirus spp. eggs on pasture $(19.7 \%)$, and the advice of veterinarians (14.5\%), although $23.7 \%$ of flock owners treated on the same day each year regardless of the other factors named above (Table 1).

\section{Potential under- or over-dosing}

Dosing to the average weight of the group/flock was practised by $10.2 \%$ of respondents and the weight of the animals was estimated by $40.3 \%$ (Table 1 ), leading to the cumulative possibility of under- or over-dosing through incorrect weight estimation in $50.5 \%$ of flocks.

Ensuring that the equipment was delivering its stated dose before treatment was routinely practised by $30.7 \%$ of respondents, whilst $52.0 \%$ occasionally checked and $17.3 \%$ of respondents never checked their equipment before treating for Nematodirus spp. infection (Table 1).

Checking that the product was within its effective lifespan before use was routinely practised by $62.7 \%$ of respondents, occasionally checked by $29.3 \%$, and never checked by $8.0 \%$ of respondents (Table 1 ).

\section{Refugia}

When asked whether every animal is treated or only a percentage of the flock is treated, $97.4 \%$ of flock owners indicated that every animal was given treatment for Nematodirus spp. infection (Table 1).

\section{Product storage}

Typically, the only storage requirements for anthelmintics are to store away from direct sunlight and within a temperature range of $4{ }^{\circ} \mathrm{C}-25{ }^{\circ} \mathrm{C}$. These conditions were satisfied by all respondents to the questionnaire: $69.9 \%$ of flock owners stored their anthelmintics in a cabinet or cupboard, $19.1 \%$ held them in either garage, shed or workshop, while the remainder $(11.0 \%)$ chose to store their products in a refrigerator (Table 1).

\section{Product use between 2009 and 2012}

The distribution of product use by product class over the 4-year time period is shown in Fig. 1. Over the surveyed period, BZ use (both as single active and in combination with a broad spectrum wormer) decreased from $44.4 \%$ in 2009 to $33.9 \%$ of all treatments given for 
Table 1 The questions posed and potential responses to the questionnaire, together with the number (N) and percentage (\%) of flock owners indicating the applicable response

\begin{tabular}{|c|c|c|}
\hline Question & Potential Response & Percentage (number of respondents \\
\hline Do you treat specifically for Nematodirus spp. infection? & $\begin{array}{l}\text { Yes } \\
\text { No }\end{array}$ & $\begin{array}{l}81.6(186) \\
18.4(42)\end{array}$ \\
\hline How is the decision made to treat the animals? & $\begin{array}{l}\text { AFBI forecast } \\
\text { Faecal egg count } \\
\text { Presence of scour } \\
\text { Advice of veterinarian } \\
\text { Advice of other farmers } \\
\text { Same day annually } \\
\text { Dependent on weather } \\
\text { At turnout } \\
\text { At } 6 \text { weeks of age } \\
\text { As needed }\end{array}$ & $\begin{array}{l}19.7(45) \\
7.9(18) \\
47.4(108) \\
14.5(33) \\
53(12) \\
23.7(54) \\
6.6(15) \\
1.3(3) \\
5.3(12) \\
5.3(12)\end{array}$ \\
\hline Is every animal treated, or is only a percentage treated? & $\begin{array}{l}100 \% \\
<100 \%\end{array}$ & $\begin{array}{l}97.4(222) \\
2.6(6)\end{array}$ \\
\hline How is the volume of drench determined? & $\begin{array}{l}\text { Estimate individual } \\
\text { Group average } \\
\text { Heaviest in group } \\
\text { Weigh individual }\end{array}$ & $\begin{array}{l}40.3(92) \\
10.2(23) \\
48.2(110) \\
1.3(3)\end{array}$ \\
\hline Is the equipment checked before use? & $\begin{array}{l}\text { Never } \\
\text { Sometimes } \\
\text { Always }\end{array}$ & $\begin{array}{l}17.3(39) \\
52.0(119) \\
30.7(70)\end{array}$ \\
\hline Where is the product stored when not in use? & $\begin{array}{l}\text { Fridge } \\
\text { Cabinet/Cupboard } \\
\text { Garage/Shed/Workshop }\end{array}$ & $\begin{array}{l}11.0(25) \\
69.9(159) \\
19.1(44)\end{array}$ \\
\hline Is "best before" date checked before use? & $\begin{array}{l}\text { Never } \\
\text { Sometimes } \\
\text { Always }\end{array}$ & $\begin{array}{l}8.0(18) \\
29.3(67) \\
62.7(143)\end{array}$ \\
\hline
\end{tabular}

(As the decision to treat is often multi-factorial, the denominator for percentage calculation is set as the number of returned questionnaires (228) and the numerator is the tally of flock owners indicating each potential response)

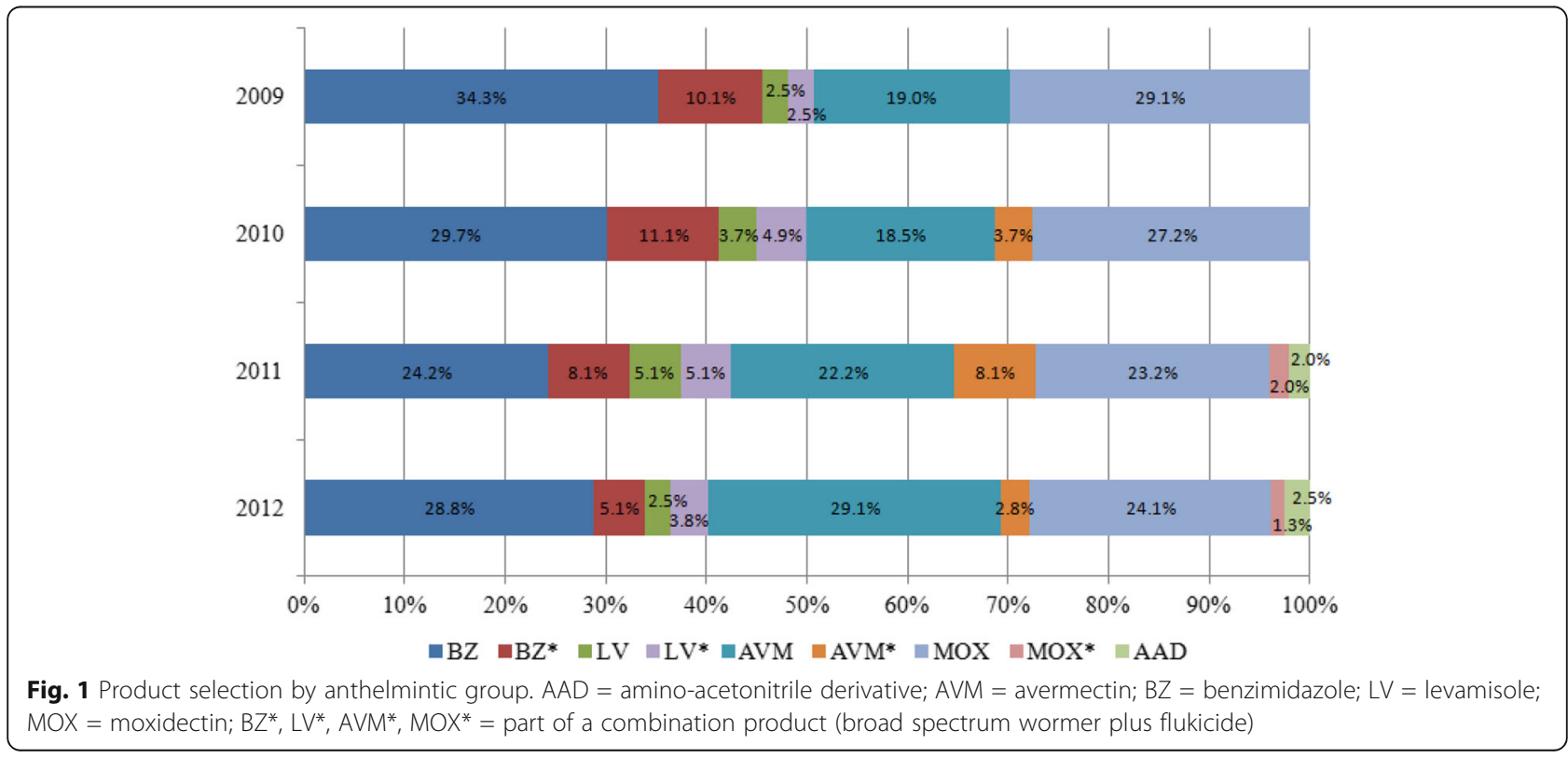


nematodirosis in 2012. Similarly, the use of moxidectin (MOX) products fell from $29.1 \%$ to $25.4 \%$ of all treatments given between 2009 and 2012, while the use of avermectin (AVM) products increased by $12.9 \%$ over the same 4-year period. The amino-acetonitrile derivative (AAD), monepantel accounted for $2.0 \%$ and $2.5 \%$ of all treatments given in the Spring of 2011 and 2012, respectively. There was no observable trend for LV use, except that (excluding monepantel) it was the least frequently used anthelmintic for the control of Nematodirus spp. infection.

\section{FECRT}

A total of 51 flock owners submitted pre-treatment faecal samples from their lambs in 2012. Of these, lambs from 41 farms had nematodirosis (as diagnosed by the presence of eggs) at the time of submission and sufficient volumes of faeces were submitted to allow the completion of the FECRT. The same 10 animals sampled at day 0 were sampled again at d 7 in 48 flocks. Within the remaining 3 flocks, only 9 of the initial 10 animals were sampled. In each case, the FEC of the replacement animal was out of character with the remainder of its dataset and was excluded from analysis. The pt. means for these 3 flocks were calculated from the remaining 9 animals. The influence that including these outliers within datasets had on efficacy calculations is summarised in Table 2.

On the basis of observed treatment efficacy alone (Fig. 2), reduced efficacy of BZs was present in $35.7 \%$ $(10 / 28)$ of flocks tested; of LV in $50 \%$ (1/2) of flocks tested; of AVMs in 33\% (2/6) of flocks tested; and of MOX in $75 \%(3 / 4)$ of flocks tested. Reduced efficacy of AAD was not detected at the time of the survey.

\section{Hatching behaviour}

After a period of 41 days, $43 \%$ of eggs in the "NonChilled" group were able to hatch, and no further hatching was observed following d 50 (data not shown). Within the "Chilled" group, 100\% of the eggs had hatched by $\mathrm{d} 21$, with the largest single increase between time points occurring between $d 9$ and d 11 (Fig. 3).

\section{Discussion}

The return rate for the Questionnaires was very high: $90.5 \%$. They were distributed to sheep farmers who had participated in a previous survey and so were not randomly selected. This could be viewed as a limitation of the study. However, the farmers were respondents to an original, random distribution of Questionnaires to 1000 farmers in the province, and the sample size was of sufficiently large size to be meaningful, so this fact should not detract from the validity of the results. Moreover, it did allow us to monitor the same group of farmers with regard to the control of various helminth parasites: gastrointestinal nematodes, liver fluke and tapeworms $[5,8,9,47]$.

\section{Control of Nematodirus}

There are a number of complex and confounding factors which influence the effectiveness of administered treatments. Broadly, they can be categorised as operational, chemical, parasitological and physiological. These areas are not mutually exclusive and many of the interactions between them play an important role in determining how effective a treatment will be at controlling the infection [48].

Adverse operational factors include treatment frequency, infrequent drug rotation, poor dosing technique, under-dosing and improperly timed treatments. Previous studies in NI have indicated that annual rotation between anthelmintics for control of ovine nematode parasites is practised by $21.3 \%$ of flock owners [8] and the majority $(61.1 \%$ of all flock owners surveyed) apply treatments up to 2 times per year [8]. Although current guidelines advise that the volume of anthelmintic given to every animal should be that given to the heaviest of the group [38], potential under- or over-dosing was identified in the present study, as $40.3 \%$ of flock owners estimated the weight of the individual animal and a further $10.2 \%$ dosed all animals according to the average of the group. Therefore, potential under- or over-dosing through incorrect weight estimation exists in 50.5\% of flocks in NI. Likewise, only $30.7 \%$ of owners checked their dosing equipment before treatment. It is recommended that flock owners incorporate local risk assessment (i.e. parasite forecasts) in their decisions regarding treatment timing to ensure optimum efficacy [39]. AFBI publishes an annual "Nematodirus forecast", advising flock owners of the projected peak hatching of eggs. It is similar to the National Animal Disease Information Service (NADIS) forecast and to that of SCOPS, in that they all make use of meteorological data and the Ollerenshaw Index [49].

Table 2 The impact of omitting outliers from mean post-treatment faecal egg counts on the efficacy of drug treatment

\begin{tabular}{|c|c|c|c|c|c|}
\hline \multirow[t]{2}{*}{ Flock code } & \multirow[t]{2}{*}{ AnthelminticGroup } & \multicolumn{2}{|l|}{ Unadjusted } & \multicolumn{2}{|l|}{ Corrected } \\
\hline & & Mean \pm S.E.M. & Efficacy (\%) (C.I.) & Mean \pm S.E.M. & Efficacy (\%) (C.I.) \\
\hline 1 & AVM & $5.3 \pm 5.3$ & $94(48,99)$ & $0 \pm 0$ & $100(100,100)$ \\
\hline 3 & $B Z$ & $6.7 \pm 4.9$ & $98(90,99)$ & $0 \pm 0$ & $100(100,100)$ \\
\hline 10 & $B Z$ & $30.3 \pm 30.3$ & $90(11,99)$ & $0 \pm 0$ & $100(100,100)$ \\
\hline
\end{tabular}

AVM avermectin, BZ benzimidazole, C.I. Confidence Intervals, Corrected outliers omitted from calculations, S.E.M. Standard Error about the Mean, Unadjusted with outliers included in calculations 


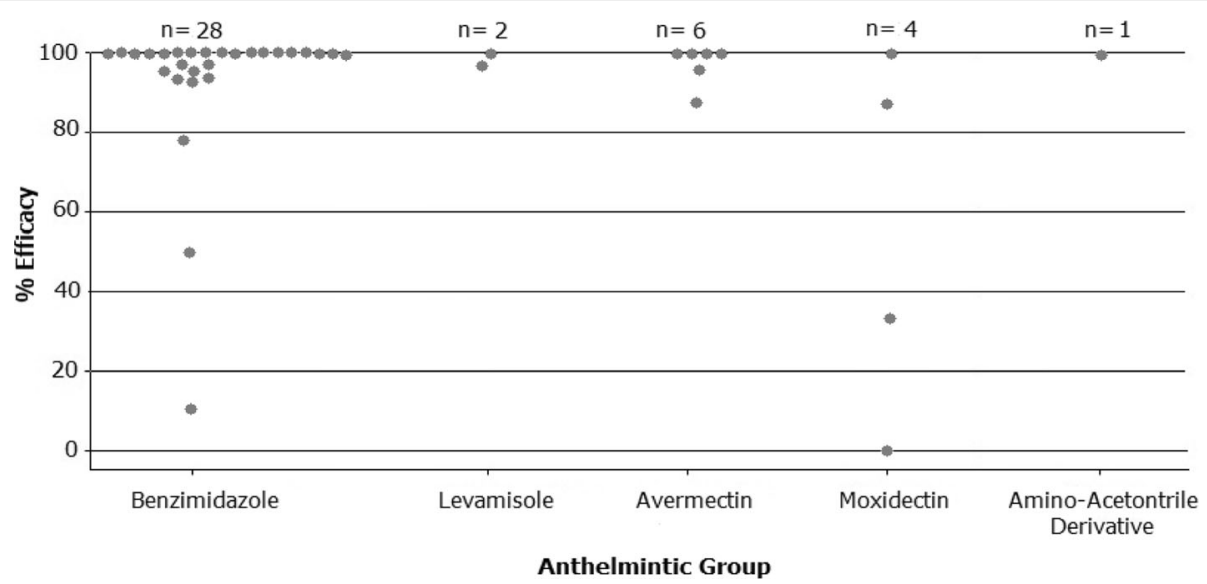

Fig. 2 Efficacies (based on Faecal Egg Count Reduction, or FECR) following treatment for Nematodirus battus with the benzimidazoles, levamisole, the avermectins, moxidectin and the amino-acetonitrile derivative, monepantel

However, the AFBI forecast focuses solely on NI, offers advice on treatments, on efficacy testing should it be required, and provides a point of contact should flock owners have queries [50]. The questionnaire data revealed that only $19.7 \%$ of owners consulted the local AFBI forecast before treatments were given; similarly, only $6.6 \%$ of respondents took account of prevailing weather conditions. Generally, it is considered unwise to await the appearance of clinical signs before therapeutic intervention [51], although a total of $52.7 \%$ of flock owners did so.

Chemical factors contributing to treatment failure include the use of generic brands, expired products, improperly stored products and persistent anthelmintics.

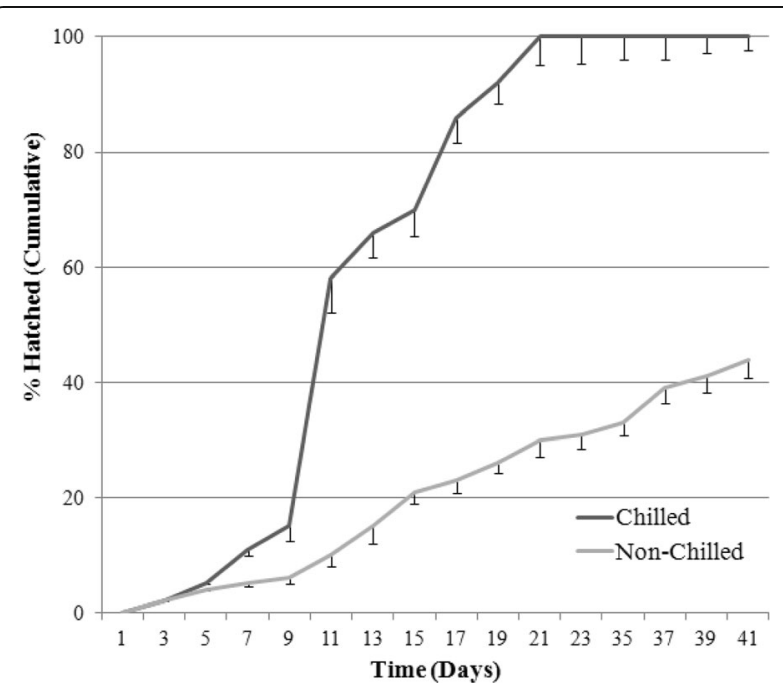

Fig. 3 Hatching behaviour at $13{ }^{\circ} \mathrm{C}$ of Nematodirus battus eggs with or without prior chilling. The Figure represents the cumulative proportion of eggs hatched between day 0 and day 41. Three replicates were conducted per batch of eggs (error bars represent the standard deviation)
The Questionnaire returns indicated that generic products were available and used in NI, but the contribution of these to treatment failure has not been assessed. Over $60 \%$ of respondents indicated that they routinely ensured the product was within its "best before" date before use, although the potential also existed for uncontrolled storage temperatures of anthelmintics in fridges $(11.0 \%$ of respondents) or in garages (19.1\% of respondents). Due to their high safety index and efficacy [38], the BZs are widely used in the control of $N$. battus [37]. In this regard, the use of a BZ reduces selection pressure on the other anthelmintic families of drugs [39]. It might increase non-target pressure on other nematode species that might be present at the time of treatment, but BZ resistance is so widespread in these species that use against $N$. battus is unlikely to exacerbate significantly the (already irretrievable) situation. Furthermore, the timing of BZ use in Spring for lambs is likely to be too early to have an impact on the other PGE species. Over the time period investigated by the questionnaire, the use of AVMs for Nematodirus spp. control increased by 12.9\% (to $31.9 \%$ : Fig. 1). This is an important point, as MLs (AVMs plus MOX) (57.3\% in 2012) are used more extensively than BZs (33.9\%); LV (6.3\%) and AAD (2.5\%) are not widely used and so are not major contributors to the potential problem of inappropriate drug choice.

\section{Ineffective control of Nematodirus in NI}

In Nematodirus spp., testing the efficacy of treatments using FECRT should, where possible, have pt. sampling occurring within 7-10 d following drench administration [39]. This is due to the brief pre-patent period of $N$. battus [52]. The World Association for the Advancement of Veterinary Parasitology (WAAVP) guidelines recommend pre-dosing egg counts of at least $150 \mathrm{epg}$ for the faecal egg count reduction test to give reliable 
evidence of resistance (based on the modified McMaster technique with minimum sensitivity of $50 \mathrm{epg}$ ). This is clearly difficult to obtain for Nematodirus spp., for which egg counts are often low and the presence or absence of even a single egg in the small sample examined could lead to over- or under-estimation of the egg count, respectively. Hence, if evidence of resistance is to be obtained, a more sensitive assay than the standard McMaster is needed. The sedimentation method allows a much larger sample to be analysed, leading to a more accurate estimation of the number of eggs present. Regular and repeated checks on the content of the $90 \mu \mathrm{m}$ sieve and on the residue passing through the $63 \mu \mathrm{m}$ sieve following sample preparation, have confirmed the efficacy of the method for retention of Nematodirus eggs and, with a detection limit of $15 \mathrm{epg}$, it is more sensitive than the modified McMaster method for the low egg counts typically found in Nematodirus infections. Other techniques now exist with greater sensitivity than the McMaster technique - eg FLOTAC, 1 epg [53] and mini-FLOTAC, 5 epg [54] - but they were not available to use at the time the present study was carried out.

While at first glance it would appear that there are a high number of holdings in NI where reduced drug efficacy is a problem, this may not in fact be the case. The five classes of anthelmintics claim efficacy against $N$. battus [55], although the parasite is a dose-limiting species for mebendazole (and other early, insoluble BZs) [27] and for most of the ML anthelmintics [37]. Reduced BZ activity was present in $35.7 \%$ of flocks tested with BZs. Potentially, this constitutes a significant problem, as the BZs are the main class of drugs used for control of nematodirosis.

Four flock owners used products containing MOX. Injectable formulations of MOX are only active against $N$. spathiger, whereas oral MOX is active against $N$. battus (and other Nematodirus spp). Three of the four flock owners used oral MOX; the other used injectable, longacting MOX. In the case of the AVMs, Dectomax, Noromectin, Oramec and Qualimec were used. Dectomax ${ }^{\odot}$ (Zoetis) will only effectively treat $\mathrm{L}_{4} N$. battus larvae when a higher dose rate (of $300 \mu \mathrm{g} / \mathrm{kg}$, not $200 \mu \mathrm{g} / \mathrm{kg}$ ) than that suggested on the packaging is used. (When contacted, the flock owner did not know this.) Ivomec ${ }^{\oplus}$ (Merial AH) and Qualimec ${ }^{\odot}$ only have a label claim against $N$. filicollis [55]. Thus, it would appear that the use of ML products to control nematodirosis should not be recommended until flock owners are more aware of the gaps in their spectra of activity.

The presence of reduced drug efficacy against $N$. battus infection in NI has highlighted a major issue and illustrates the problem that farmers have to deal with. Significantly, it reflects the reality of what is happening in the field. One possible explanation for this state of affairs is the existence of AR in $N$. battus populations, but that has not been demonstrated in the present study.

\section{Anthelmintic resistance in Nematodirus spp., across the British isles and the ROI}

Results of a survey conducted in the ROI in 2013 revealed reduced treatment efficacy against Nematodirus spp. While BZs were effective in $100 \%$ of tests, LV was effective in $80 \%$ of cases and ML (AVM plus MOX) treatment was effective in $94 \%$ of cases [34]. No details were given regarding which ML products were used, but the authors noted that Nematodirus spp. is the dose-limiting species for that anthelmintic group and this may account for the lower efficacy of MLs in some cases.

In a preliminary investigation into a case of suspected BZ resistance in $N$. battus, in the North of England, it was shown that treatment with fenbendazole reduced the FEC by $83 \%$ [36]. Faecal material from the farm with suspected BZ resistance was subsequently used to generate parasite material for a clinical efficacy trial, which confirmed the presence of AR [37].

\section{Hatching requirements}

Within-genotype variation has been put forward as a hypothesis regarding the diversity of hatching requirements observed in a similar study in the UK [20]. This represents a viable hypothesis as, in the present study, any eggs collected throughout the Spring infection would be the offspring of larvae which had hatched after a chilling stimulus; the good weather conditions (mean daily temperatures of $13.5{ }^{\circ} \mathrm{C}, 13.3{ }^{\circ} \mathrm{C}$ and $11.1{ }^{\circ} \mathrm{C}$ in August, September and October, respectively) for hatching in the Autumn months preceding sample collection in the Spring of 2012 precluded the prospect that the Spring infections arose from eggs not requiring chilling (i.e. those which had been unable to hatch during the previous Autumn); and larvae from eggs hatching in Autumn would not have survived the winter. As stated by van Dijk and Morgan [20], "The eggs collected for the experiments, therefore, must have been produced by nematodes hatching from eggs that had delayed hatching until after exposure to a chilling stimulus".

Previously, we have discussed the shift in focus away from the classical Spring bell-curve of Nematodirus spp. infection towards Autumn infections. This shift was consistent with increasing monthly temperatures [4]. How the incidence of one affects the incidence of the other is not yet clear, but some reports suggest a positive correlation between the heights of the Spring and Autumn peaks of diagnoses within the same year [56]. While Autumn hatching and N. battus infection does occur in NI, probably it is not a disease entity in its own right, but would occur as an element of PGE at that time. The 
animals are older and larger, and more resilient, so the clinical problems (of diarrhoea and death) are not likely to be as severe as spring nematodirosis.

\section{Conclusions}

The results of the questionnaire survey on control of Nematodirus identified a number of poor control strategies, namely, inappropriate product choice, underdosing and inaccurate calibration of dosing equipment. This highlights the need for continued education of flock owners and a greater awareness by them of the range of efficacies of those products that are available. An unsuitable choice of anthelmintic has implications, not just for control of Nematodirus, but for the development of AR in off-target species as well. In the short-term, the use of BZs over AVMs should be promoted for the control of nematodirosis, in order to reduce the pressure on the AVM group. Stockholders should also make better use of forecasting information and show greater vigilance in monitoring parasitic infections. They should be encouraged to submit samples for diagnosis to ensure optimal treatment timing and detection of AR. The early detection of AR would allow maximal time to implement effective control strategies aimed at reducing further development of resistance [57]. The results of the coprological survey have highlighted the problem of reduced activity of anthelmintics used to treat Nematodirus infections and this may indicate that AR exists in Nematodirus populations in NI. The latter requires more rigorous investigation before it can be confirmed. This is particularly true for LV, AVM and MOX, as only a small number of farms were involved in the present study and so the results should be interpreted with some degree of caution.

The results obtained in the hatching study suggest that a diversity of behaviours exists. This may indicate within-genotype variation in the chilling requirement and, as such, further investigations into the long-term effects of climate change on parasitism, flock health plans and anthelmintic use are warranted. The existence of a second autumnal infection, and its importance relative to the Spring infection, requires ongoing monitoring and is something farmers should be aware of. Clearly, signs of scour in the autumn would not necessarily alert farmers to the possibility of $N$. battus infection and they would most likely be using MLs, not BZs, because of the need to treat other nematode species (at that time). Consequently, accurate diagnosis of $N$. battus at this time is essential, as is better education of farmers to be more aware of an autumnal infection.

If appropriate measures are put in place, AR should not develop in Nematodirus spp. to the same extent as already reported for Trichostrongylus spp. and T. circumcincta in NI [7]. While Nematodirus spp. may not be seen to be as significant as these species, its successful control is still of great importance to the health of young lambs in the flock.

Finally, while the present communication completes the overview of ovine helminth disease in NI, it contributes to a greater all-island of Ireland perspective on disease control in Ireland. The data may help to inform the design and implementation of future management programmes.

\begin{abstract}
Abbreviations
AAD: Amino-acetonitrile derivative; AFBl: Agri-Food and Biosciences Institute; AR: Anthelmintic resistance; AVM: Avermectin; BZ: Benzimidazole; CAFRE: College of Agriculture, Food and Rural Enterprise;

DAERA: Department of Agriculture, Environment and Rural Affairs;

DAFM: Department of Agriculture, Food and the Marine; FEC: Faecal Egg

Count; FECRT: Faecal Egg Count Reduction Test; GVA: Gross added value;

LV: Levamisole; MAFF: Ministry of Agriculture, Fisheries and Food;

ML: Macrocyclic lactone; MOX: Moxidectin; NADIS: National Animal Disease Information Service; NI: Northern Ireland; NIFDA: Northern Ireland Food and Drink Association; NOAH: National Office of Animal Health; PGE: Parasitic gastroenteritis; pt.: Post-treatment; ROI: Republic of Ireland; SAC: Scottish Agricultural College; SCOPS: Sustainable Control of Parasites in Sheep; SNP: Single nucleotide polymorphism; UK: United Kingdom; VSD: Veterinary Sciences Division; WAAVP: World Association for the Advancement of Veterinary Parasitology
\end{abstract}

\section{Acknowledgements \\ We wish to thank Robert Walker and David McCoubrey (AFBI) who helped disseminate the questionnaire, Mary Devlin and Jennie Finlay from the School of Biological Sciences, QUB, Don Morrow and Steven Johnston, from the College of Agriculture, Food and Rural Enterprise (CAFRE), William Sherrard formerly at Pfizer, and all the farmers who participated in the survey, without whom this work would not have been possible.}

\section{Funding}

None

\section{Availability of data and materials}

The datasets used and analysed during the current study are available in the PhD Thesis of Connor McMahon, held in the Library of The Queen's University of Belfast.

McMahon, C. 2015. Anthelmintic resistance in parasites of sheep in Northern Ireland and the strategic control of parasitic diseases.

\section{Authors' contributions}

$\mathrm{CM}, \mathrm{HE}, \mathrm{RH}$ and IF contributed to study design and the analysis and interpretation of data. $\mathrm{CM}, \mathrm{RH}, \mathrm{GB}$ and IF were involved in drafting the manuscript. CM, JB, RH and IF gave final approval of the version to be published. CM, RH and IF agreed to be accountable for all aspects of the work. All authors read and approved the final manuscript.

Ethics approval and consent to participate

Not applicable

\section{Consent for publication \\ Not applicable}

\section{Competing interests}

The authors declare that they have no competing interests.

\section{Publisher's Note}

Springer Nature remains neutral with regard to jurisdictional claims in published maps and institutional affiliations.

\section{Author details}

${ }^{1}$ Parasite Therapeutics Research Group, School of Biological Sciences, Medical Biology Centre, The Queen's University of Belfast, 97 Lisburn Road, Belfast 
BT9 7BL, UK. ${ }^{2}$ Veterinary Sciences Division, Agri-Food and Biosciences Institute (AFBI) Stormont, Belfast BT4 3SD, UK.

\section{Received: 30 January 2017 Accepted: 10 October 2017 Published online: 19 October 2017}

\section{References}

1. Anon. Ulster Bank quarterly economic review, April 2010.

2. NIFDA (Northern Ireland Food and Drink Association). The Agri-food sector: role in the Northern Ireland economy. 2012. www.nifda.co.uk.

3. DAERA (Department of Agriculture, Environment and Rural Affairs). Statistical review of Northern Ireland Agriculture. 2015. https://www.daera-ni.gov.uk/sites/ default/files/publications/DARD/stats-review-2015-final-amended.PDF.

4. McMahon C, Gordon AW, Edgar HWJ, Hanna REB, Brennan GP, Fairweather I. The effect of climate change on parasitic gastroenteritis determined using veterinary surveillance and meteorological data for Northern Ireland over the period 1999-2009. Vet Parasitol. 2012;190:167-77.

5. McMahon C, Edgar HWJ, Hanna REB, Ellison SE, Flanagan AM, McCoy M, Kajugu P-E, Gordon AW, Irwin D, Barley JE, Malone FE, Brennan GP, Fairweather I. Liver fluke control on sheep farms in Northern Ireland: a survey of changing management practices in relation to disease prevalence and perceived triclabendazole resistance. Vet Parasitol. 2016;216:72-83.

6. Cooper KM, McMahon C, Fairweather I, Elliott CT. Potential impacts of climate change on veterinary medicinal residues in livestock produce: an island of Ireland perspective. Trends Food Sci Tech. 2015;44:21-35.

7. McMahon C, Bartley DJ, Edgar HWJ, Ellison SE, Barley JP, Malone FE, Hanna REB, Brennan GP, Fairweather I. Anthelmintic resistance in Northern Ireland (I): prevalence of resistance in ovine gastrointestinal nematodes, as determined through faecal egg count reduction testing. Vet Parasitol. 2013c;195:122-30.

8. McMahon C, Barley JP, Edgar HWJ, Ellison SE, Hanna REB, Malone FE, Brennan GP, Fairweather I. Anthelmintic resistance in Northern Ireland (II): variations in nematode control practices between lowland and upland sheep flocks. Vet Parasitol. 2013a;192:173-82.

9. McMahon C, McCoy M, Ellison SE, Barley JP, Edgar HWJ, Hanna REB, Malone FE, Brennan GP, Fairweather I. Anthelmintic resistance in Northern Ireland (III): uptake of "SCOPS" (Sustainable Control of Parasites in Sheep) recommendations by sheep farmers. Vet Parasitol. 2013b;193:179-84.

10. Haskell SSR. Blackwell's five-minute veterinary consult: ruminant. lowa: Wiley-Blackwell.

11. Thomas RJ, Stevens AJ. Some observations on Nematodirus disease in Northumberland and Durham. Vet Rec. 1956;68:471-5.

12. Christie MG. On the hatching of Nematodirus battus, with some remarks on N. fillicollis. Parasitology. 1962;52:297-313.

13. Winter MD, Wright $C$, Lee $D L$. The effect of dexamethasone on resistance of older lambs to infection with Nematodirus battus. J Helminthol. 1997;71:133-8.

14. Sutherland I, Scott I. Gastrointestinal nematodes of sheep and cattle, biology and control. Oxford: Blackwell Publishing; 2010.

15. Roeber F, Jex AR, Gasser RB. Impact of gastrointestinal parasitic nematodes of sheep and the role of advanced molecular tools for exploring epidemiology and drug resistance - an Australian perspective. Parasite Vector. 2013;6:153

16. $\mathrm{AFBI}$ (Agri-Food and Biosciences Institute). All-island animal disease surveillance report. 2013. www.afbini.gov.uk/.

17. AFBI (Agri-Food and Biosciences Institute). All-island animal disease surveillance report. 2014. www.afbini.gov.uk/.

18. AFBI (Agri-Food and Biosciences Institute). All-island animal disease surveillance report. 2015. www.afbini.gov.uk/.

19. van Dijk J, Morgan ER. The influence of temperature on the development, hatching and survival of Nematodirus battus larvae. Parasitology. 2008;135:269-83.

20. van Dijk J, Morgan ER. Variation in the hatching behaviour of Nematodirus battus: polymorphic bet hedging? Int J Parasitol. 2010;40:675-81.

21. Anon. Nematodirosis a major problem in Scottish flocks in June. -SAC veterinary services - surveillance report. Vet Rec. 2005;157:273-6.

22. Anon. SAC C VS disease surveillance report: cases of nematodirosis in lambs peak in June. Vet Rec. 2011;168:581-4.

23. Anon. Northern Ireland disease surveillance report: Northern Ireland disease surveillance, January to March 2013. Vet Rec. 2013;172:657-8.
24. Anon. AHVLA disease surveillance report: widespread reporting of parasitic gastroenteritis in sheep. Vet Rec. 2014;174:10-3.

25. Bartley D, Kenyon F, Jackson F. Nematodirus: a perennial (but changing?) problem in lambs. 2011. The Moredun Foundation News Sheet, Vol. 5, No. 9.

26. Scottish Agricultural Colleges (SAC). Veterinary services disease surveillance report. Vet Rec. 2011;168:122-5.

27. Sargison ND, Wilson DJ, Scott PR. Observations on the epidemiology of autumn nematodirosis in weaned lambs in a Scottish sheep flock. Vet Rec 2012;170:391.

28. Middelberg A, McKenna PB. Oxfendazole resistance in Nematodirus spathiger. New Zeal Vet J. 1983;31:65-6.

29. Martin PJ. Nematode control schemes and anthelmintic resistance. In: Anderson N, Waller PJ, editors. Resistance in Nematodes to Anthelmintic Drugs. CSIRO Division of Animal Health. Glebe, New South Wales: Australian Wool Corporation Technical Publication; 1985. p. 29-40.

30. Obendorf DL, Parsons J, Nicholls J. An egg development test for the evaluation of benzimidazole resistance in Nematodirus spathiger. Aust Vet J. 1986;66:382-3

31. Obendorf DL, Nicholls J, Koen T, Lacy E. Benzimidazole resistant Nematodirus sp. in Tasmania. Aust Vet J. 1991;68:72-3.

32. Oliver AMB, Pomroy WE, Leathwick DM. Benzimidazole resistance in Nematodirus spathiger and N. filicollis in New Zealand. New Zeal Vet J. 2016; 64:201-6.

33. Sargison ND. Nematodirosis. UK Vet. 2006;11:56-62.

34. Keane OM, Keegan JD, Good B, de Waal T, Fanning J, Gottstein M, Casey M, Christine $H$, Sheehan M. High level of treatment failure with commonly used anthelmintics on Irish sheep farms. Ir Vet J. 2014;67:16.

35. Keegan JD, Keane OM, Good B, de Waal T, Denny M, Hanranahan JP, Fitzgerald W, Sheehan M. A nationwide survey of anthelmintic treatment failure on sheep farms in Ireland. Ir Vet J. 2017;70:7.

36. Mitchell S, Mearns R, Richards I, Donnan A, Bartley DJ. Benzmidazole resistance in Nematodirus battus. Vet Rec. 2011:168:623.

37. Morrison AA, Mitchell S, Mearns R, Richards I, Matthews JB, Bartley DJ. Phenotypic and genotypic analysis of benzimidazole resistance in the ovine parasite Nematodirus battus. Vet Res. 2014;45:116.

38. Abbott KA, Taylor MA, Stubbings LA. Sustainable control of parasites in sheep (SCOPS), a technical manual for veterinary surgeons and advisors. 4th ed; 2012. www.nationalsheep.org.uk.

39. Stubbings L. Benzimidazole resistance in Nematodirus battus. Vet Rec. 2011; 168:623-4.

40. SCOPS. NEMATODIRUS IN LAMBS. 2012. http://scops.org.uk/alert_pdfs/ NEMATODIRUSApril201204042012090139.pdf.

41. Flanagan A, Edgar HWJ, Gordon A, Hanna REB, Brennan GP, Fairweather I. Comparison of two assays, a faecal egg count reduction test (FECRT) and a coproantigen reduction test (CRT), for the diagnosis of resistance to triclabendazole in Fasciola hepatica in sheep. Vet Parasitol 2011;176:170-6.

42. Kohapakdee S, Pandey VS, Pralomkarn W, Choldumrongkul S, Ngampongsai W, Lawpetchara S. Anthelmintic resistance in goats in southern Thailand. Vet Rec. 1995:137:124-5.

43. Bartley DJ, Donnan AA, Jackson E, Sargison N, Mitchell GBB, Jackson F. A small scale survey of ivermectin resistance in sheep nematodes using the faecal egg count reduction terst on samples collected from Scottish sheep. Vet Parasitol. 2006:137:112-8.

44. Coles GC, Bauer C, Borgsteede FHM, Geerts S, Klei TR, Taylor MA, Waller PJ. World Association for the Advancement of Veterinary Parasitology (WAAVP) methods for the detection of anthelmintic resistance in nematodes of Veterinary importance. Vet Parasitol. 1992:44:35-44.

45. van Wyk JA, Mayhew E. Morphological identification of parasitic nematode infective larvae of small ruminants and cattle: a practical lab guide. Onderstepoort J Vet Res. 2013;80:14 pages.

46. Ministry of Agriculture, Fisheries and Food. Manual of veterinary parasitological laboratory techniques. London: Her Majesty's Stationery Office; 1986.

47. McMahon C, Edgar HWJ, Barley JP, Hanna REB, Brennan GP, Fairweather I. Tapeworm control practices by sheep farmers in Northern Ireland. Vet Parasitol: Reg Studies and Reps. 2017;7:14-8.

48. Bartley DJ. The prevalences, characterisation and management of anthelmintic resistance in gastrointestinal nematodes in Scottish Sheep. PhD Thesis. Edinburgh: University of Edinburgh; 2008.

49. Ollerenshaw CB, Smith LP. An empirical approach to forecasting the incidence of nematodiriasis over England and Wales. Vet Rec. 1966;79:536-40. 
50. Edgar H, Barley J, Hanna R. AFBI issues Nematodirus warning - Spring 2016. 2016. https://www.afbini.gov.uk/news/afbi-issues-nematodirus-warning-spring-2016.

51. Taylor MA, Coop RL, Wall RL. Veterinary Parasitology. 3rd ed. Oxford: Blackwell Publishing Ltd.; 2007.

52. Thomas RJ. A comparative study of the life histories of Nematodirus battus and N. filicollis, nematode parasites of sheep. Parasitology. 1959:49:374-86.

53. Cringoli G, Rinaldi L, Maurelli MP, Utzinger J. FLOTAC: new multivalent technique for qualitative and quantitative copromicroscopic diagnosis of parasites in animals and humans. Nat Protoc. 2010;5:503-15.

54. Rinaldi L, Levecke B, Bosco A, lanniello D, Pepe P, Charlier J, Cringoli G, Vercruysse J. Comparison of individual and pooled faecal samples in sheep for the assessment of gastrointestinal strongyle infection intensity and anthelmintic drug efficacy using McMaster and mini-FLOTAC. Vet Parasitol. 2014;205:216-23.

55. NOAH (National Office of Animal Health). 2016. http://www. noahcompendium.co.uk.

56. NADIS (National Animal Disease Information Service). 2013. http://webinars. nadis.org.uk/media/4198/13-05__parasite_forecast.pdf.

57. Richards I. Benzimidazole resistance in Nematodirus battus. Vet Rec. 2011;169:108

Submit your next manuscript to BioMed Central and we will help you at every step:

- We accept pre-submission inquiries

- Our selector tool helps you to find the most relevant journal

- We provide round the clock customer support

- Convenient online submission

- Thorough peer review

- Inclusion in PubMed and all major indexing services

- Maximum visibility for your research

Submit your manuscript at www.biomedcentral.com/submit
Biomed Central 